\title{
Biochemical and Molecular Genetic Characterization of a New Variant Prealbumin Associated with Hereditary Amyloidosis
}

\author{
Margaret R. Wallace, Francis E. Dwulet, P. Michael Conneally, and Merrill D. Benson \\ Departments of Medicine, Medical Genetics and Biochemistry, Rheumatology Division, Indiana University School of Medicine, \\ Richard L. Roudebush Veterans Administration Medical Center, Indianapolis, Indiana 46202
}

\begin{abstract}
Familial amyloidotic polyneuropathy (FAP) is an autosomal dominant late-onset disorder characterized by the extracellular deposition of amyloid fibrils. In all cases studied these fibrils have been found to be composed of plasma prealbumin (transthyretin) containing a single amino acid substitution. Biochemical studies were conducted on amyloid from one patient and plasma prealbumin from his affected brother, both part of a large kindred from the Appalachian region of the United States. Sequence analysis of the amyloid subunit protein showed it to be prealbumin with about two-thirds of the molecules containing a substitution of alanine for threonine at position 60 . Studies of the plasma prealbumin showed that the same substitution was present in $40-45 \%$ of the protein. Based on this substitution and the prealbumin cDNA sequence, a Pvu II restriction fragment length DNA polymorphism (RFLP) was predicted and demonstrated in DNA of both patients as well as other family members. This RFLP confirms the predicted DNA mutation responsible for the protein variant, and represents an accurate method for detection of this gene.
\end{abstract}

\section{Introduction}

Over the last several decades hereditary amyloidosis (familial amyloidotic polyneuropathy, FAP) ${ }^{1}$ has been identified in a number of kindreds. While these disorders have a worldwide distribution, they all express a symmetrical polyneuropathy to varying degrees. They differ, however, with respect to the degree of cardiac, renal, intestinal and other organ involvement. Originally the kindreds were classified by symptomology and national origin (1). Recently, however, a number of these amyloidoses have been biochemically characterized, and to date all FAP amyloids have been found to be composed of variant prealbumin (transthyretin) molecules. The most common of these syndromes is FAP type I, which has been reported in Sweden, Japan, Portugal, and the United States (2-4). This amyloid is composed

Presented in part at the American Society of Human Genetics 1985 Annual Meeting. (1985. Am. J. Hum. Genet. 37:A20. Abstr.)

Address reprint requests to Dr. Benson, Chief, Rheumatology Section, Richard L. Roudebush Veterans Administration Medical Center, 1481 West 10th Street, Indianapolis, IN 46202.

Received for publication 27 January 1986.

1. Abbreviations used in this paper: FAP, familial amyloidotic polyneuropathy; HPLC, high performance liquid chromatography; RFLP, restriction fragment length polymorphism; SSC, $0.15 \mathrm{M} \mathrm{NaCl}, 0.015 \mathrm{M}$ sodium citrate, $\mathrm{pH} 7.0 ; \mathrm{TE}, 0.01 \mathrm{M}$ Tris, $0.001 \mathrm{M}$ EDTA.

The Journal of Clinical Investigation, Inc.

Volume 78 , July $1986,6-12$ of prealbumin with a substitution of methionine for valine at position 30 of the 127 amino acid prealbumin monomer (5-9). Quite recently FAP type II amyloid has been identified as containing prealbumin with the substitution of serine for isoleucine at position 84 (10). Lastly, an FAP amyloid of Jewish origin has been shown to contain a prealbumin variant with an isoleucine for phenylalanine substitution at position $33(11)$; although previous reports indicate that it may also have a glycine for threonine at position $49(12,13)$. It would seem that most if not all of the FAP syndromes are the result of specific variant prealbumin molecules and that the different clinical expressions of these diseases appear to be, in part at least, the result of the specific amino acid substitutions.

We recently identified a new FAP kindred from the Appalachian region of the United States. These affected individuals have major depositions of amyloid in cardiac tissue similar to FAP type II, but otherwise appear to have a unique disease progression. This report presents our findings on the biochemical characterization of this amyloid and its plasma prealbumin precursor as well as the development of a DNA screening technique to identify preclinical carriers of the trait.

\section{Methods}

Amyloid fibrils were isolated from cardiac tissue of a 65 -yr-old man who died of restrictive cardiomyopathy after the diagnosis of amyloidosis had been made by rectal and bladder biopsies. Family history revealed that both his father and uncle had died with amyloidosis after age 60 . Shortly after the proband's death, one of his brothers, aged $58 \mathrm{yr}$, developed angina and congestive heart failure. Amyloidosis was diagnosed by rectal biopsy and the brother donated plasma for study. Blood for DNA extraction had been obtained from both brothers and 14 close relatives.

Amyloid fibrils were isolated from the proband's heart tissue and the amyloid subunit protein purified as previously described (14). $2 \mathrm{mg}$ of this protein were dissolved in $0.1 \mathrm{M}$ ammonium bicarbonate, and $2 \%$ (wt/wt) trypsin (Worthington Biochemicals, Freehold, NJ) was added (5). The reaction proceeded at room temperature for $8 \mathrm{~h}$, and the solution was then lyophilized. This peptide mixture was dissolved in $25 \%$ acetic acid and applied to a SynChrom RP-8 column $(1 \mathrm{~cm} \times 25 \mathrm{~cm}$; SynChrom, Inc., Linden, IN). An acetonitrile gradient was used to elute the peptides, which were identified by absorbance at $215 \mathrm{~nm}$.

An aliquot of each peptide was subjected to hydrolysis in $5.7 \mathrm{~N} \mathrm{HCl}$ at $110^{\circ} \mathrm{C}$ for $24 \mathrm{~h}$ and amino acid composition determined on a Beckman 119C amino acid analyzer (Beckman Instruments, Inc., Fullerton, CA). Peptides were sequenced with a Beckman $890 \mathrm{C}$ liquid phase protein sequenator using the 0.1-M quadrol program (121078) with the addition of $3 \mathrm{mg}$ of polybrene to each sample to reduce extractive losses.

Prealbumin was isolated from the brother's plasma using a three-step procedure as described elsewhere (15). The protein was digested with trypsin, fractionated on high performance liquid chromatography (HPLC) and the tryptic peptides subjected to amino acid analysis and sequencing as done for the amyloid protein.

For the DNA analysis, total genomic DNA was extracted from leukocytes from 16 members of the kindred (16). In the initial test for the 
hypothesized polymorphism, $10 \mu \mathrm{g}$ of the proband's DNA and a normal control DNA were used. These were digested to completion with Pvu II (Bethesda Research Laboratories, Gaithersburg, MD). The fragmented DNA was precipitated in $0.3 \mathrm{M}$ sodium acetate and ethanol, centrifuged, and the pellets dried under vacuum. The pellets were redissolved in TE buffer (0.01 M Tris, pH 8.0, and 0.001 M EDTA), and the DNA fragments separated by electrophoresis through a $0.8 \%$ agarose gel. Hind III fragments of phage lambda DNA were used as molecular weight standards.

DNA was denatured in the gel with $0.5 \mathrm{M} \mathrm{NaOH} / 1.5 \mathrm{M} \mathrm{NaCl}$ and transferred to a nitrocellulose filter by the method of Southern (17). The filter was then baked at $80^{\circ} \mathrm{C}$ for $2 \mathrm{~h}$ under vacuum and prehybridized at $65^{\circ} \mathrm{C}$ in the following solution: $6 \times \mathrm{SSC}=0.15 \mathrm{M} \mathrm{NaCl}, 0.015 \mathrm{M}$ sodium citrate, $\mathrm{pH} 7.0,1 \times$ Denhardt's solution $(50 \times=1 \%$ Ficoll, $1 \%$ polyvinylpyrrolidone, $1 \%$ bovine serum albumin, BSA), $0.1 \%$ sodium dodecyl sulfate (SDS), $100 \mu \mathrm{g} / \mathrm{ml}$ sheared salmon sperm DNA, and 0.05 $\mathrm{M}$ sodium phosphate, $\mathrm{pH} 7.0$.

Prealbumin cDNA (150 ng) was radiolabeled by nick translation using alpha- $\left[{ }^{32} \mathrm{P}\right] \mathrm{dCTP}$ (deoxycytidine triphosphate, New England Nuclear, Boston, MA) $(18,19)$. The filter was hybridized with this probe $\left(5 \times 10^{7} \mathrm{cpm}\right)$ in $10 \mathrm{ml}$ of hybridization solution in a heat-sealed plastic bag for $48 \mathrm{~h}$ at $65^{\circ} \mathrm{C}$. The filter was washed in a series of increasingly stringent solutions $(6 \times$ SSC, $3 \times$ SSC, $1 \times$ SSC, $0.2 \times$ SSC) containing $0.3 \%$ SDS at $65^{\circ} \mathrm{C}$, and autoradiographed using Kodak XAR film (Eastman Kodak Co., Rochester, NY) at $-70^{\circ} \mathrm{C}$.

After the results from above were returned, DNA from the rest of the family was analyzed with this technique.

\section{Results}

Congo red staining of autopsy material revealed extensive amyloid deposition in the cardiac tissue. From $30 \mathrm{~g}$ of tissue (wet wt) $150 \mathrm{mg}$ of amyloid fibrils were recovered from supernates of homogenizations in distilled water, and $2.1 \mathrm{~g}$ recovered from the pellets. After staining with Congo red both fractions were found to be highly enriched for amyloid fibrils. Amyloid fibrils from the water supernate $(100 \mathrm{mg}$ ) were denatured in $6 \mathrm{M}$ guanidine, reduced, and alkylated and fractionated on Sepharose CL6B. From $100 \mathrm{mg}$ of fibrils, $8 \mathrm{mg}$ of a low molecular weight subunit protein was isolated, accounting for $15 \%$ of the recovered proteins. On SDS-polyacrylamide gel electrophoresis (PAGE) the subunit protein peak showed a single band with a molecular mass of $14,000 \mathrm{D}$. Sequence analysis of the subunit protein revealed a very heterogeneous structure from which the parent protein could not easily be determined. Prealbumin was isolated from the plasma of the propositus' brother and $7 \mathrm{mg}$ was recovered from $100 \mathrm{ml}$. This represented a recovery of $\sim 30 \%$ when compared with the serum prealbumin concentration determined by radial immunodiffusion.

HPLC separation of the tryptic peptides of the amyloid fibril protein and plasma prealbumin on a reverse-phase column resulted in profiles nearly identical to normal prealbumin (Fig. 1). The only difference from normal was the presence of two variant peaks, $7^{*}$ and $7 *-8$, which eluted slightly later than peptides 7 and 7-8, respectively. Peptides 7 and 7-8 correspond to amino acid residues $49-70$ and $49-76$, where 7-8 is the product of incomplete digestion between peptides 7 and 8 . These data suggested that $7 *$ and $7 *-8$ represented variants of 7 and $7-8$, which localized the hypothesized amino acid substitution to the 4970 region of the protein. Magnitudes of the peaks indicated that approximately two-thirds of the prealbumin peptides from the amyloid fibrils contained the variant, while $\sim 40-45 \%$ of the plasma prealbumin peptides contained the variant.

Amino acid analysis of peptides $7^{*}$ and $77_{-8}$ indicated that each lacked one threonine and had an additional alanine, com- pared with the normal peptides 7 and 7-8 (Table I). All other tryptic peptides appeared to have normal composition. Sequencing analysis showed that all peptides except the two variants had sequences consistent with normal prealbumin. The variant peptides were shown to contain an alanine at position 60 in place of the normal threonine (Fig. 2).

This substitution, previously unreported, is consistent with the proven association of FAP and prealbumin variants. Examination of the prealbumin cDNA sequence and the genetic code revealed that this protein polymorphism would most likely correspond to a point mutation of $A$ to $G$ in the first position of the threonine codon (18). Analysis of the cDNA sequence in this region revealed that this base change creates the palindromic sequence CAGCTG, which is a recognition site for Pvu II. Since this enzyme does not cut the normal prealbumin gene at this location, we predicted a $P v u I I$ restriction fragment length polymorphism (RFLP) specific for the described mutation.

DNA analysis of the proband (lane $P$ ) and a normal control (lane $N$ ) is seen in Fig. $3 a$. In lane $P$, three $P v u I I$ fragments are detected by the prealbumin cDNA probe: $5.8,5.2$, and 3.7 kilobases (kb). Lane $N$ shows only the 5.8 - and $3.7-\mathrm{kb}$ fragments. In addition the $5.8-\mathrm{kb}$ band of lane $P$ is only half the intensity of the same band from $N$, and is equal in intensity to the variant $5.2-\mathrm{kb}$ band.

A total of 15 other family members, including the affected brother, was screened for this DNA polymorphism. 6 of these 15 were found to have the variant RFLP, including the affected brother, a sister (as yet unaffected), and a niece, grandson, and two children of the proband (Fig. $3 b$ ). Testing of several other normal control DNAs as well as DNA from FAP type I and type II patients revealed only the normal two-band pattern.

\section{Discussion}

As with FAP type II, extraction of cardiac tissue gave large amounts of amyloid fibrils in the pelleted material but little in the water extracts. Also, the elution profile (on Sepharose CL6B) for the isolation of the amyloid subunit protein was similar to that reported for FAP type II. Sequence analysis of the amyloid subunit protein revealed a heterogeneous amino acid sequence. Analysis of the yield data revealed that $\sim 40 \%$ of the polypeptide chains started at position 4 of the prealbumin molecule. Of the remaining structures $\sim 25 \%$ originated at position 1 and positions 2,3 , and 5 each accounted for $8-12 \%$ of the molecular structure. A similar $\mathrm{N}$-terminal heterogenicity for amyloid subunit prealbumins has been reported by Skinner and Cohen, Tawara et al., and Kametani et al. (6-8). The HPLC elution profile of the trypsin digested amyloid subunit protein (Fig. 1) was also homologous to that seen for FAP type II in that there was poor recovery of peptides T2 (10-15), T5-6 (35-48), and T6 (36-48), which is probably the result of the oxidation of the cysteine 10 , methionine 13 , and tryptophan 41 . This finding is similar to that found in FAP type II (Indiana/Swiss) protein, which was also isolated from cardiac tissue (10). Of the remaining peptides only peaks $7^{*}$ and $7^{*}-8$ were found to be unique. Sequence analysis revealed that both peptides started at position 49 , and at position 60 of the prealbumin molecule an alanine was found instead of the normal threonine. In the amyloid subunit protein this variant peptide accounted for about two-thirds of the peptide chains. This is quite consistent with that seen for the other FAP amyloids $(5,9)$. For the plasma prealbumin trypsin digest, except 
a
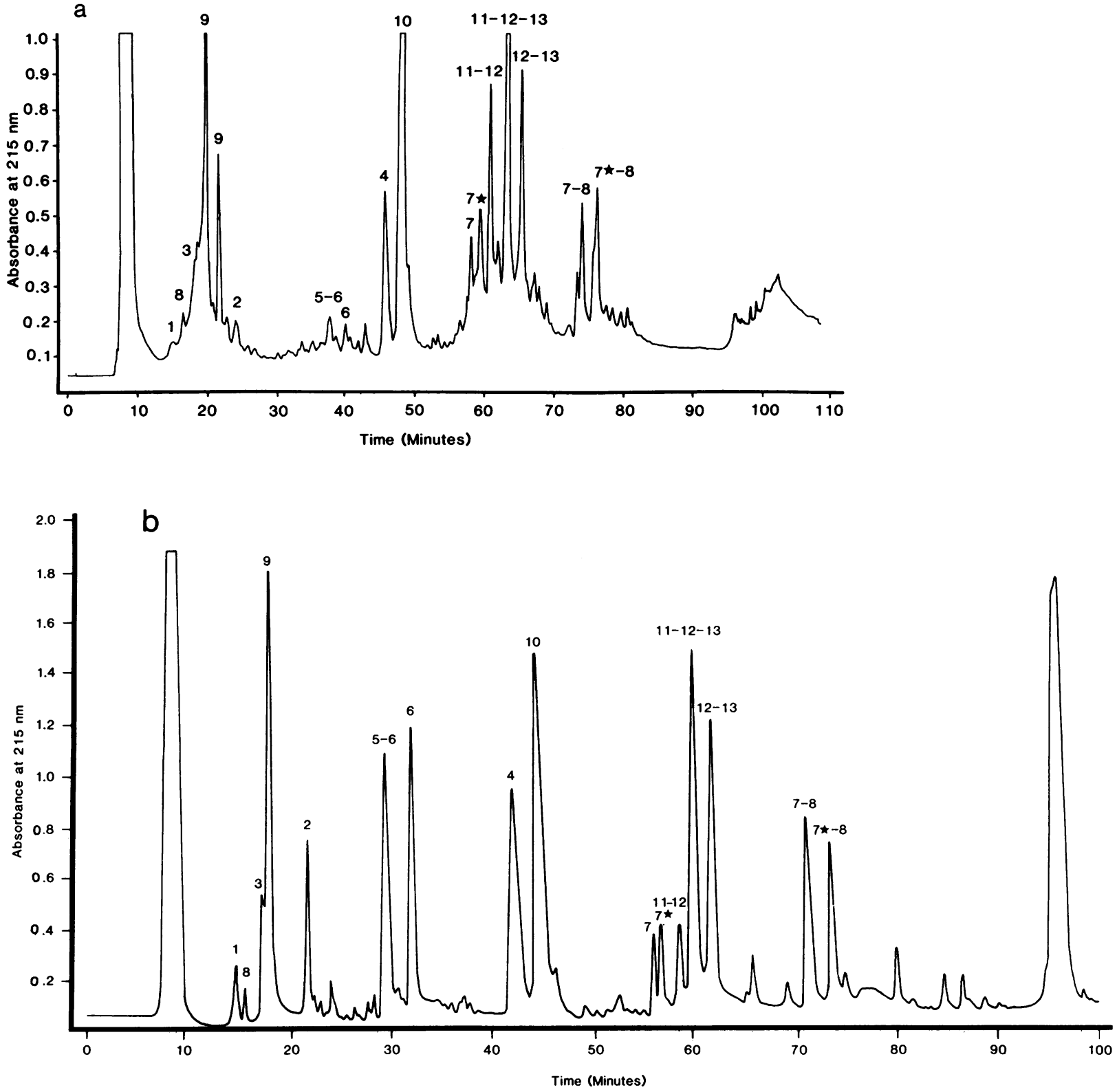

Figure 1. (a) Reverse-phase HPLC separation of peptides derived from trypsin digestion of $2 \mathrm{mg}$ of amyloid subunit protein on a column $(1 \times 25$ $\mathrm{cm}$ ) of Synchrom RP-8 resin. The column was equilibrated in $0.1 \%$ trifluoroacetic acid and the peptides eluted with a linear gradient of 0-35\% acetonitrile formed during a $75-\mathrm{min}$ period. The column was maintained at room temperature $\left(21^{\circ} \mathrm{C}\right)$ with a flow rate of $2 \mathrm{ml} / \mathrm{min}$. All peptides are numbered sequentially from the amino terminal. Peptides T2, T5-6, and T6 were recovered in low yield probably due to oxidation of methionine and tryptophan. (b) Reverse-phase HPLC separation of peptides formed by trypsin digestion of $3 \mathrm{mg}$ of plasma prealbumin. Column and conditions same as above. This profile is identical to that seen for normal prealbumin except for the presence of peptides $T 7^{*}$ and $T 7^{*}-8$.

for the presence of peptides $\mathrm{T} 7^{*}$ and $\mathrm{T} 7^{*}-8$, a pattern identical to that from normal prealbumin was seen (Fig. 1). These variant peptides accounted for almost $45 \%$ of the prealbumin molecules. This is unusual because most individuals who are clinically affected with FAP have $25 \%$ or less of the variant prealbumin in their plasma $(9,15)$. This unusually high level of variant may be related to the slow rate of disease progression in this kindred. On a molecular level this substitution occurs near the middle of the D-E loop (20). This segment of the molecule has limited molecular interactions and how this substitution affects the structure of the molecule is not readily apparent.

According to a recent study the prealbumin gene is present as a single copy in the human genome (21). The 5.8 and $3.7 \mathrm{~kb}$ fragments from normal human DNA indicate that the cDNA probe detects one $P v u I I$ cut within the normal prealbumin gene. The additional 5.2-kb fragment and the decreased intensity of the 5.8-kb fragment in the DNA of the affected brothers indicates that these individuals are heterozygous at the prealbumin locus. As hypothesized, the abnormal (FAP) gene contains an extra $P v u$ II site, which reduces the $5.8-\mathrm{kb}$ fragment to $5.2 \mathrm{~kb}$. From the reported genomic sequence, the remaining 600-base fragment is nearly all intron sequence and so is not detected by the cDNA probe under these conditions.

This characterization of a variant prealbumin with alanine 


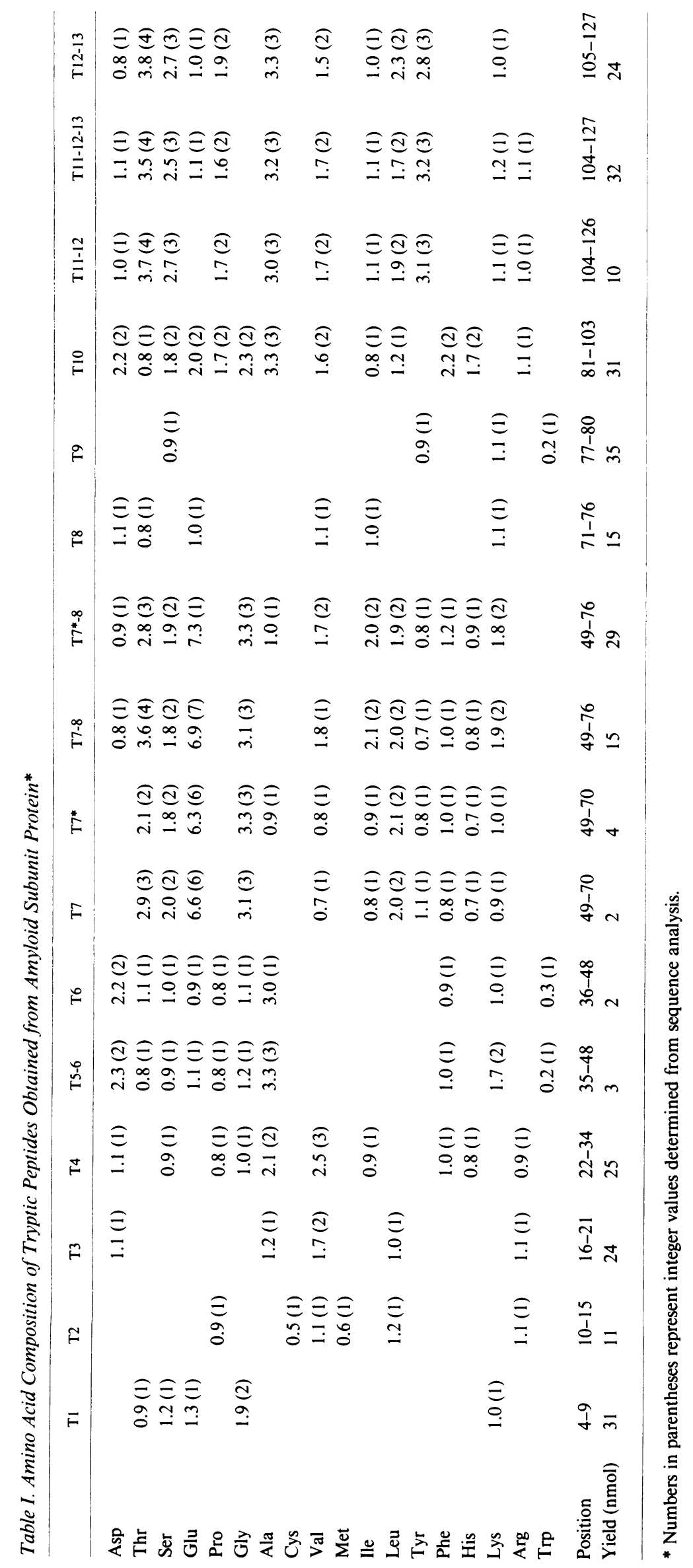


Gly-Glu- Leu- His- Gly-Leu-Thr-Thr-Glu-Glu-Glu-Phe-Val-Glu-Gly-Ile-Tyr-Lys-Val-Glu-Ile-Asp-Thr-Lys-Ser-Tyr-

Figure 2. The complete amino acid sequence of the isolated amyloid subunit protein and the tryptic peptides used to determine the structure. The sequence information obtained from each peptide is shown by an arrow under the respective fragments. Since the amino terminal is heterogeneous, the data obtained for the major sequence starting at position 4 are shown.

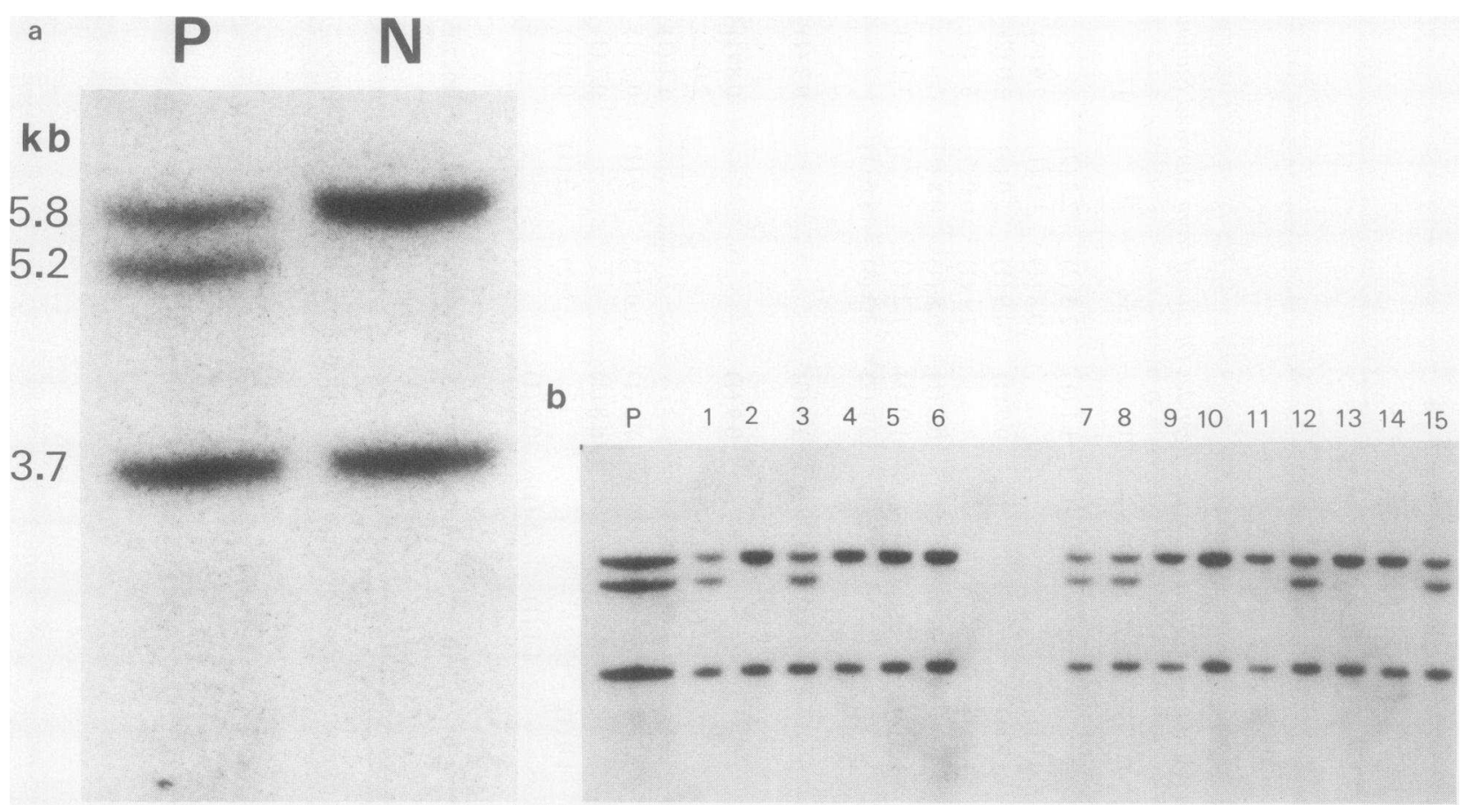

Figure 3. (a) Autoradiograph of Southern analysis of $P v u$ II-digested DNA from proband (lane $P$ ) and control (lane $N$ ). The probe was prealbumin cDNA nick translated with $\left.{ }^{32} \mathrm{P}\right] \mathrm{dCTP}$. Fragment sizes (in kilobases) are indicated to the left of lane $P$. (b) Southern analysis of $P v u I I$-digested DNA from the family of the proband. The variant prealbumin fragment (5.2 kb) is detected in lanes $P$ (proband), 8 (brother), and lanes 1 , $3,7,12$, and 15. Fragment sizes correspond to those indicated in $(a)$. 
at position 60 associated with hereditary amyloidosis brings to four the number of reported prealbumin variants that are associated with amyloid formation (10-12, 15). This lays a firm basis for biochemically classifying the autosomal dominant amyloidoses and shows that, in general, the older classification by clinical expression of disease was basically sound. It has now been shown that FAP type I (polyneuropathy in the lower limbs associated with severe autonomic dysfunction), which was classically described in Portuguese, Japanese, and Swedish patients, is associated with a prealbumin variant with methionine substituted for valine at position 30 of the molecule. This mutation has been confirmed by DNA analysis using restriction endonucleases $\mathrm{Nsi} I$ and $\mathrm{Bal} I$ (22). The Indiana/Swiss FAP type II, which is characterized by cardiomyopathy, prominent eye involvement and low serum retinol binding protein levels, is associated with a serine substitution at position 84 of the prealbumin molecule (23). The Jewish FAP, which was originally reported to have a glycine for threonine substitution at position 49 , has more recently been reported to have an isoleucine for phenylalanine at position 33 . Whether both substitutions are present in the Jewish FAP prealbumin gene or this represents multiple variant alleles has not been resolved. All of the variants except for glycine at 49 can be explained by single base changes. The new Appalachian type of FAP, with an alanine substitution at position 60, appears clinically distinct from FAP type I and type II and indeed is a separate chemical abnormality.

There are a number of clinically described hereditary amyloidoses that have yet to be characterized. The Maryland kindreds that are similar clinically to the Indiana/Swiss have not yet been characterized chemically and neither has the Iowa kindred where amyloidosis is associated with nephrotic syndrome and a high incidence of peptic ulcer disease $(24,25)$. FAP in a large family described by Koeppen et al. in New York is associated with prealbumin amyloid deposits but is not chemically characterized, and a number of families in Sweden, France, and the United States have yet to be studied chemically $(2,26,27)$. The chances of finding more prealbumin variants associated with hereditary amyloidosis seem quite likely. On the other hand, variations in the clinical syndrome between kindreds with the same genetic defect must lead us to studies of other factors that control amyloid formation. Variation in age of onset, tissue distribution of amyloid deposits, and progression of the disease complex must be explained by factors other than the single nucleotide mutation in the gene for prealbumin. An understanding of these factors may well be important in devising methods of altering the progression of the disease in affected individuals.

The characterization of the genetic abnormality in the Appalachian type of FAP is a classic example of clinical research. It started with a recognition by attending physicians that it is important to study such diseases and that there are methods for such studies. The isolation of amyloid fibrils and characterization of the primary structure of the prealbumin subunit was straightforward. Knowing the genetic code for prealbumin allowed the postulation of a unique restriction enzyme ( $P v u I I)$ recognition site in the variant gene, and the availability of the cDNA probe allowed the characterization of this FAP-specific RFLP. While the DNA analysis would have been difficult without first having the protein structure data, it is obviously the superior way of detecting the genetic abnormality in individuals who are at risk for FAP. Certainly it should be adaptable to the prenatal detection of gene carriers and, in addition, it will give a basis for genetic counseling of individuals who are at risk.

\section{Acknowledgments}

The authors thank Marilyn Smith and Gretchen Bowker for technical assistance and Carol Kauchak for secretarial assistance.

This work was supported by Veterans Administration Medical Research (MRIS 583-0888), and grants from RR-00750 (GCRC), United States Public Health Service, National Institute of Arthritis, Diabetes, and Digestive and Kidney Diseases (AM 20582 and AM 7448), the Arthritis Foundation, the Grace M. Showalter Trust, the Marion E. Jacobson Fund, the National Science Foundation, and Sigma Xi.

\section{References}

1. Andrade, A., S. Araki, W. D. Block, A. S. Cohen, C. E. Jackson, Y. Kuroiwa, V. A. McKusick, J. Nissim, E. Sohar, and M. W. VanAllen. 1970. Hereditary amyloidosis. Arthritis Rheum. 13:902-915.

2. Andersson, R. 1970. Hereditary amyloidosis with polyneuropathy. Acta Med. Scand. 188:85-94.

3. Andrade, C. 1952. A peculiar form of peripheral neuropathy. Familial atypical generalized amyloidosis with special involvement of the peripheral nerves. Brain. 75:408-427.

4. Benson, M. D., and A. S. Cohen. 1977. Generalized amyloid in a family of Swedish origin-a study of $\mathbf{4 2 6}$ family members in seven generations of a new kinship with neuropathy, nephropathy and central nervous system involvement. Ann. Intern. Med. 86:419-424.

5. Dwulet, F. E., and M. D. Benson. 1984. Primary structure of an amyloid prealbumin and its plasma precursor in a heredofamilial polyneuropathy of Swedish origin. Proc. Natl. Acad. Sci. USA. 81:694-698.

6. Skinner, M., and A. S. Cohen. 1981. The prealbumin nature of the amyloid protein in familial amyloid polyneuropathy (FAP)—Swedish variety. Biochem. Biophys. Res. Commun. 99:1326-1332.

7. Tawara, S., M. Nakazato, K. Kangawa, H. Matsuo, and S. Araki. 1983. Identification of amyloid prealbumin variant in familial amyloidotic polyneuropathy (Japanese type). Biochem. Biophys. Res. Commun. 116:880-888.

8. Kametani, F., H. Tonoike, A. Hoshi, T. Shinoda, and S. Kito. 1984. A variant prealbumin-related low molecular weight amyloid fibril protein in familial amyloid polyneuropathy of Japanese origin. Biochem. Biophys. Res. Commun. 125:622-628.

9. Saraiva, M. J. M., S. Birken, P. P. Costa, and D. S. Goodman. 1984. Amyloid fibril protein in familial amyloidotic polyneuropathy Portuguese type. J. Clin. Invest. 74:104-119.

10. Benson, M. D., and F. E. Dwulet. 1985. Identification of a new amino acid substitution in plasma prealbumin associated with hereditary amyloidosis. Clin. Res. 33:590a. (Abstr.)

11. Nakazato, M., K. Kangawa, N. Minamino, S. Tawara, H. Matsuo, and S. Araki. 1984. Revised analysis of amino acid replacement in a prealbumin variant (SKO-III) associated with familial amyloidotic polyneuropathy of Jewish origin. Biochem. Biophys. Res. Commun. 123: 921-928.

12. Pras, M., E. C. Franklin, F. Prelli, and B. Frangione. 1981. A variant of prealbumin from amyloid fibrils in familial polyneuropathy of Jewish origin. J. Exp. Med. 154:989-993.

13. Pras, M., F. Prelli, E. C. Franklin, and B. Frangione. 1983. Primary structure of an amyloid prealbumin variant in familial polyneuropathy of Jewish origin. Proc. Natl. Acad. Sci. USA. 80:539-542.

14. Benson, M. D. 1981. Partial amino acid sequence homology between an heredofamilial amyloid protein and human plasma prealbumin. J. Clin. Invest. 67:1035-1041.

15. Dwulet, F. E., and M. D. Benson. 1983. Polymorphism of human plasma thyroxine binding prealbumin. Biochem. Biophys. Res. Commun. 114:657-662.

16. Hoar, D. I. 1981. A compilation of techniques for molecular diagnosis and the "new genetics." Biologue. 1:2-5.

17. Southern, E. M. 1975. Detection of specific sequences among DNA fragments separated by gel electrophoresis. J. Mol. Biol. 98:503517.

18. Wallace, M. R., S. L. Naylor, B. Kluve-Beckerman, G. L. Long, 
L. McDonald, T. B. Shows, and M. D. Benson. 1985. Localization of the human prealbumin gene to chromosome 18. Biochem. Biophys. Res. Commun. 129:753-758.

19. Rigby, P. W. J., M. Dieckmann, C. Rhodes, and P. Berg. 1977. Labelling deoxyribonucleic acid to a high specific activity in vitro by nick translation with DNA polymerase I. J. Mol. Biol. 113:237-251.

20. Blake, C. C. F., M. J. Geisow, and S. J. Oatley. 1978. Structure of prealbumin: secondary, tertiary and quarternary interactions determined by fourier refinement at 1.8A. J. Mol. Biol. 121:339-356.

21. Tsuzuki, T., S. Mita, S. Maeda, S. Araki, and K. Shimada. 1985. Structure of the human prealbumin gene. J. Biol. Chem. 260:12,22412,227 .

22. Sasaki, H., Y. Sakaki, H. Matsuo, I. Goto, Y. Kuroiwa, I. Sahashi, A. Takahashi, T. Shinoda, T. Isobe, and Y. Takagi, 1984. Diagnosis of familial amyloidotic polyneuropathy by recombinant DNA techniques. Biochem. Biophys. Res. Commun. 125:636-642.
23. Benson, M. D., and F. E. Dwulet. 1983. Prealbumin and retinol binding protein serum concentrations in the Indiana type hereditary amyloidosis. Arthritis Rheum. 26:1493-1498.

24. Mahloudji, M., R. D. Teasdall, J. J. Adamkiewicz, W. H. Hartman, P. A. Lambird, and V. A. McKusick. 1969. The genetic amyloidoses: with particular reference to hereditary neuropathic, type II (Indiana or Rukavina type). Medicine (Baltimore). 48:1-37.

25. Van Allen, M. W., J. A. Frohlich, and J. R. Davis. 1969. Inherited predisposition to generalized amyloidosis. Neurology. 19:10-25.

26. Koeppen, A. H., E. J. Mitzen, M. B. Hans, S. Peng, and R. D. Bailey. 1985. Familial amyloid polyneuropathy. Muscle Nerve. 8:733749.

27. Julien, J., C. Vital, J. M. Vallat, A. Lagueny, and X. Ferrer. 1983. Neuropathies amyloides familiales dans trois familles d'origine francaise. Rev. Neurol. (Paris). 139:259-267. 